Revista Iberoamericana, Vol. LXVIII, Núm. 200, Julio-Septiembre 2002, 847-864

\title{
POSOCCIDENTALISMO: \\ LAS EPISTEMOLOGÍAS FRONTERIZAS Y EL DILEMA DE LOS ESTUDIOS (LATINOAMERICANOS) DE ÁREA
}

POR

\author{
Walter D. Mignolo \\ Duke University
}

El argumento que sigue es una continuación de cuestiones que comenzaron a preocuparme después de la conclusión de The Darker Side of the Renaissance: Literacy, Territoriality and Colonization (1995), sobre todo del "afterword" ("On Modernity, Colonization and the Rise of Occidentalism”). Esta reflexión se continuó en un artículo previo publicado en esta misma revista (Mignolo 1995; ver también Mignolo 1994-1996). Tuvo también mucha importancia en esta serie de reflexiones la resistencia que encontré, en América Latina, a la idea de poscolonialidad en seminarios y conferencias que ofrecí en Puebla (México); Bogotá y Cartagena (Colombia); y Buenos Aires (Argentina). En Brasil (Río de Janeiro, Salvador y Minais Gerais), la acogida fue más favorable. Indirectamente, este artículo es una continuación de la conversación con Santiago CastroGómez por correo electrónico, que se concretó luego en un capítulo de un libro (CastroGómez 1996); de forma interrumpida (por carta, fax y correo electrónico) en los dos últimos años, con Roberto Fernández Retamar. En Duke es un diálogo continuado con Alberto Moreiras y, en particular, con dos de sus últimos artículos (Moreiras 1996a, 1996b). Finalmente, intento aquí continuar la línea de apertura hacia la reflexión crítica sobre el colonialismo y la modernidad abierta por Stuart Hall en los estudios culturales (Hall 1991 a, 1991b), y continuar descentrando la localización geográfica y epistemológica del conocimiento; regionalizando "posmodernismo" y "poscolonialismo" mediante la invitación a la fiesta de alguien olvidado, el "posoccidentalismo”.

Agregar un "pos” más a la pléyade ya existente quizás suene como una invitación al cansancio. Sin embargo, este aparentemente nuevo "pos" no es tan nuevo. Roberto Fernández-Retamar acudió a la palabra-clave cuando publicó uno de sus artículos clásicos, "Nuestra América y Occidente” (Retamar 1976). La palabra-clave aparece, en el artículo de Retamar, como una consecuencia lógica de su revisión del pensamiento en América Latina desde el siglo XIX en un intento de "definir el ámbito histórico de nuestra América” (Retamar 1976, 36). El esfuerzo, como veremos un poco mas adelante, no es una mera cuestión de verdad histórica, sino de categorías geoculturales y sus relaciones con el conocimiento y el poder. Pues bien, el repaso histórico que hace Fernández Retamar del pensamiento en América Latina desde el siglo XIX hasta 1976, muestra que una de las preocupaciones fundamentales fueron las relaciones entre América Latina y Europa, al menos hasta 1898, y las relaciones de América Latina y América sajona desde y a partir 
de 1898, momento en el que los esfuerzos locales y los proyectos de independencia en Puerto Rico y Cuba se encontraron en un nuevo orden mundial y en una situación muy diferente a la de los movimientos de independencia al comienzo del siglo XIX. El paulatino ingreso de Estados Unidos a la escena mundial, y el paulatino receso de España del orden imperial, se reorganizan precisamente hacia fin de siglo, cuando Cuba y Puerto Rico tienen que cambiar sus proyectos históricos, entrecruzados con nuevos conflictos imperiales. A partir de ese momento ya no es posible hablar de la independencia de los países de América Latina como si esta se definiera por los casos históricos, en América hispana y lusitana, de las primeras décadas del siglo XIX cuando la liberación de España implicaba, para muchos y al mismo tiempo, la celebración de lazos económicos y culturales con Francia e Inglaterra, muchas veces ignorando las implicaciones históricas de liberarse de un imperio decadente y entrar en negociaciones con imperios emergentes. A finales del siglo XIX nos encontramos con un escenario mundial en el que los imperios emergentes a principios de ese mismo siglo son testigos de una nueva fuerza imperial que llegará a su apogeo medio siglo más tarde, después de la segunda guerra mundial. Para los pensadores en América Latina el cruce y superposición de poderes imperiales se concibió no tanto en términos de colonización sino de occidentalización. Es por esta razón que “posoccidentalismo” (en vez de "posmodernismo” y “poscolonialismo”) es una palabra que encuentra su lugar "natural” en la trayectoria del pensamiento en América Latina, así como "posmodernismo" y "poscolonialismo" lo encuentra en Europa-Estados Unidos y en ex-colonias británicas, respectivamente (Mignolo 1996). No se trata de reclamar autenticidades y lugares de origen, sino de meras trayectorias históricas y de derechos de ciudadanía: por ejemplo, la resistencia que “poscolonialismo” encontró y todavía encuentra en América Latina y en ciertos sectores de los estudios latinoamericanos en Estados Unidos. "posoccidentalismo" puede designar la reflexión crítica sobre la situación histórica de América Latina que emerge durante el siglo XIX, cuando se van redefiniendo las relaciones con Europa y gestando el discurso de la "identidad latinoamericana", pasando por el ingreso de Estados Unidos, hasta la situación actual en que el término adquiere una nueva dimensión debido a la inserción del capitalismo en “Oriente” (este y sureste de Asia).

Recordemos el contexto en el cual Fernández Retamar introdujo la palabra-clave "posoccidentalismo":

\footnotetext{
La idea de que los latinoamericanos verdaderos "no somos europeos", es decir, "occidentales", ya había encontrado en este siglo sostenedores enérgicos, sobre todo entre los voceros de comunidades tan visiblemente no "occidentales" como los descendientes de los aborígenes y de los africanos. Los grandes enclaves indígenas de nuestra América (que en algunos países son una "minoría nacional” que constituye una mayoría real) no requieren argumentar esa realidad obvia: herederos directos de las primeras víctimas de lo que Martí llamó “civilización devastadora”, sobreviven a la destrucción de sus civilizaciones como pruebas vivientes de la bárbara irrupción de otra civilización en estas tierras (Fernández Retamar 1976, 51).
}

Sin duda que en 1976 era menos problemático pensar que se pudiera hablar de "latinoamericanos verdaderos". El hecho de que hoy lo sea es una consecuencia particular 
del proceso creciente de globalización (quizás no ya de occidentalización) planetaria y del incremento tanto de los capitales transnacionales como de la migraciones masivas que ponen en tela de juicio categorías que permitían afincar gente y entes abstractos concebidos como “culturas”, a territorios. La cosificación del concepto de cultura, y la gestación de entes como las culturas nacionales (continentales o subcontinentales) fue y es una parte integral de la idea misma de occidentalismo, de la construcción de occidente como el símismo, y del resto del planeta como la otredad.

El espacio entre el sí-mismo y el otro se construyó sobre la base de considerar las culturas como entes encerrados en territorios nacionales. La transnacionalización del capital y su desarraigo nacional, tanto como las migraciones motivadas por la transnacionalización económica, fractura cada vez más la idea de que las culturas son entidades coherentes localizables en unidades geográficas discretas. La expresión común “conocer o comprender otras culturas” (sobre todo en Estados Unidos) es cada vez más problemática. Pues bien, a pesar de que hoy nos sea difícil aceptar sin más la autenticidad de "latinoamericanos verdaderos", el párrafo citado pone de relieve y de forma clara, el problema de la occidentalización y de América Latina como una entidad geocultural creada por los diseños imperiales, que se fue configurando conflictivamente en ese mismo proceso de occidentalización. Es en esa encrucijada (o mejor, en esa zona fronteriza), que se produce la tensión entre lo que se considera propio y lo que se considera ajeno, en la que los intelectuales en América Latina reflexionaron críticamente sobre la occidentalización con posterioridad a las independencias de España y Portugal, cuando era necesario construir la nación y para ello era necesaria una educación y una política educativa que integrara los proyectos nacionales y continentales. El hecho de que la palabra-clave fuera y todavía sea “occidentalización” u “occidentalismo” se debe a los legados del discurso imperial mismo, para el cual las posesiones ultramarinas de Castilla y Portugal se categorizaban como "Indias Occidentales” y no, claro está, como “América” concebida por los letrados al norte de los Pirineos, que no tenían influencia alguna en los proyectos imperiales de Castilla.

El párrafo citado más arriba prepara el terreno para la introducción de la palabra-clave “posoccidentalismo” que Fernández Retamar introduce de esta manera:

Indios y negros, pues, lejos de constituir cuerpos extraños a nuestra América por no ser "occidentales", pertenecen a ella con pleno derecho: más que los extranjerizos y descastados "civilizadores". Y era natural que esto fuera plenamente revelado o enfatizado por pensadores marxistas, pues con la aparición en la Europa occidental del marxismo, en la segunda mitad del siglo XIX, y con su ulterior enriquecimiento leninista, ha surgido un pensamiento que sienta en el banquillo al capitalismo, es decir, al mundo occidental. Este pensamiento sólo podría brotar en el seno de aquel mundo, que en su desarrollo generó a su sepulturero, el proletariado y su consiguiente ideología: pero esta no es ya una ideología occidental, sino en todo caso posoccidental: por ello hace posible la plena comprensión, la plena superación de Occidente, y en consecuencia dota al mundo no occidental del instrumento idóneo para entender cabalmente su dramática realidad y sobrepasarla. En el caso de la América Latina, ello se hace patente cuando el marxismoleninismo es asumido y desarrollado por figuras heráldicas como el peruano José Carlos Mariátegui y los cubanos Julio Antonio Mella y Rubén Martínez Villena (Fernández Retamar 1976, 52). 
Veinte años después de escrito este párrafo, es difícil aceptar que el posoccidentalismo, como proyecto de trascender el occidentalismo, pueda concebirse sobre la base de una ideología del proletariado, y que se acepte tal ideología como no-occidental. El elemento faltante son las relaciones entre etnicidad y trabajo, antes de la revolución industrial y la emergencia del proletariado. Las relaciones entre etnicidad y trabajo están presentes desde los primeros momentos de la expansión occidental, cuando la explotación de los amerindios en las minas es complementada por la importación de esclavos africanos a las nuevas tierras descubiertas. Al integrar etnicidad y trabajo de esta forma, la reflexión crítica y la búsqueda de trascedencia del occidentalismo se enraiza en el mero momento en que el discurso imperial de la modernidad (expulsión de los árabes y judíos, explotación de los amerindios y tráfico de esclavos) se funda y comienza a fundar estructuras de poder sobre el principio de la "pureza de sangre" y de la “unidad del idioma”. Tanto algunas reflexiones del mismo Carlos Marx sobre el colonialismo en India (en las cuales consideraba a Inglaterra la primera civilización superior que conquistara India, después de las sucesivas conquistas de los árabes, los turcos, los tártaros y los mongoles, que fueron "hinduizadas" (Marx 1853)), la experiencia histórica en la práctica del socialismo, los genocidios perpetuados a lo largo de la modernidad e implementados en torno a cuestiones éticas, la creciente fuerza que ganan las ideologías forjadas en torno a cuestiones de género sexual y de sexualidad, mantienen sin duda la necesidad de un posoccidentalismo como horizonte, en donde las represiones forjadas y surgidas de las expansiones coloniales, justificadas en los ideales del Renacimiento (cristianización), de la Ilustración(civilización) o de la modernización (tecnología y consumismo), puedan ir trascendiéndose. El pesimismo que pueda generar, al mismo tiempo, la globalización actual y el capitalismo sin fronteras, no es un argumento suficiente para pensar que el posoccidentalismo es una quimera intelectual. Los movimientos sociales siguen creciendo en número y diversidad, a tal punto de que ya no es posible pensar que sólo el proletariado sea un movimiento con fuerza de transformación social, y que la sociedad del futuro seguirá reproduciendo las estructuras de poder en la distinción Occidente-Oriente, con todas las implicaciones de convertir diferencias en valores, lo cual fue una de las estrategias fundamentales de subalternización implementada por el occidentalismo, como discurso y práctica político-económica.

Cuatro años después de publicado el artículo de Retamar, Oscar del Barco, filósofo argentino, disidente del PC a comienzos del 60 y co-fundador de la importante Pasado y presente (Córdoba, 1963), publicó un libro sobre Lenin (del Barco, 1980), en el que esbozó una tendencia dominante de la teoría y práctica leninista conducente a Stalin y al gulag. La reflexión de del Barco, que se funda en el poder de control que Lenin le otorgó a la teoría y al conocimiento para tomar decisiones de arriba hacia abajo y en la inclinación de Lenin a tomar — sobre esa base-decisiones autoritarias, conduce a poner de relieve el hecho de que la teoría puede convertirse en una fuerza material de control y de justificación de decisiones, lo cual ocurrió en la política bolchevique. Tal crítica no le impidió a del Barco reconocer que no hay un socialismo bueno (el de Marx) y un socialismo malo (el soviético), o una esencia marxista que se cumple o se traiciona en distintas ocasiones. Por el contrario, le permitió enfatizar que "lo que hay” son las luchas constantes de quienes están reprimidos u oprimidos y que, en ese contexto, 


\begin{abstract}
Marx es el nombre que llevan esas luchas, ese "destino" y es el nombre que la clase le ha puesto a su propio pensamiento. No se trata, por lo tanto, ni de una persona ni de un dogma Marx planteó la verdadera encrucijada de nuestra época cuando decía "socialismo o barbarie”. Los intelectuales pueden lamentarse creyendo que la barbarie ya ha triunfado; y efectivamente existen muchos signos de que la barbarie puede ser definitiva; pero las clases oprimidas, que convierten en teorías sus necesidades y esperanzas, no tienen otro horizonte que el de la lucha. Los intelectuales de hoy desaparecerán, pero los oprimidos seguirán elaborando teorías que les permitan orientarse en busca del triunfo (del Barco 1980, 182).
\end{abstract}

El vocabulario de del Barco limita quizás el alcance de su propuesta. “Clases oprimidas” universaliza la opresión en términos de clase social solamente, cuando sabemos hoy que las personas, los grupos, las comunidades oprimidas atraviesan las clases hacia arriba y hacia abajo; como lo hace también cierta manera de entender la "ideología" en los regímenes dictatoriales, que reprimen, torturan y asesinan sin distinción de clase, género, edad o etnicidad. Los regímenes dictatoriales en América Latina durante los años de la guerra fría, por ejemplo, hicieron poco caso a la distinción de clases, no reprimieron sólo a los proletarios, sino a todo aquel que se considerara comunista, montonero o guerrillero. Finalmente, si los intelectuales de hoy pueden desaparecer, como lo sugiere del Barco, pueden hacerlo por dos razones: porque — por un lado- los intelectuales mismos nos vamos convirtiendo en un movimiento social más y —por otro- porque podemos pertenecer a otros movimientos sociales (de carácter étnico, sexual, ambiental, etc.) en donde o bien nuestro rol de intelectual desaparece o bien se minimiza en la medida en que, como bien lo dice del Barco, los movimientos sociales que trabajan contra las formas de opresión y en favor de condiciones satisfactorias de vida, teorizan a partir de su misma práctica sin necesidad ya de teorías desde arriba que guíen esa práctica. La rearticulación de las relaciones entre prácticas sociales y prácticas teóricas es un aspecto fundamental del posoccidentalismo como condición histórica y horizonte intelectual.

El ejemplo de del Barco viene a cuento para contextualizar el artículo de Retamar en un momento de enorme energía y producción intelectual en América Latina, la cual tiende a desdibujarse en la escena internacional debido a la fuerza hegemónica del inglés, como idioma, y de la discusión en tomo al posmodernismo y del poscolonialismo, fundamentalmente llevada adelante en inglés. Si bien el libro de del Barco se publicó en el 80, es el resultado de discusiones y conflictos que atraviesan los años 60 y 70 . En la transición entre las dos décadas, la teoría de la dependencia (en sociología y economía) y la teoría del colonialismo interno (en sociología y antropología), complementan el escenario de la producción intelectual en América Latina. Ambas, teoría de la dependencia y del colonialismo interno, son a su manera reflexiones “posoccidentales” en la medida en que buscan proyectos que trasciendan las dificultades y los límites del occidentalismo. Ambas, teoría de la dependencia y del colonialismo interno, son respuestas a los nuevos proyectos de occidentalización que llevan ya no el nombre de "cristianización” o de “misión civilizadora” sino de "desarrollo” (Escobar 1994). Sin embargo, esta historia no se cuenta de esta manera y, sobre todo con la teoría de la dependencia, tiende a integrarse a otra historia: la historia (no del posoccidentalismo como trayectoria de pensamiento crítico en América Latina) sino a los estudios de área. En esa operación, una dramática 
colonización intelectual se lleva adelante: América Latina deja de ser el lugar donde se producen teorías, para continuar siendo el lugar que se estudia. Al hacer de la obra de Gunder Frank (1969) el token de la teoría de la dependencia en Estados Unidos, ésta se convirtió, al mismo tiempo, en un cambio de mirada: la mirada desde el norte que convierte a América Latina en un área para ser estudiada más que un espacio donde se produce pensamiento crítico. Lamentablemente, esta imagen continúa vigente en esfuerzos recientes como el de Berger, en el cual la teoría de la dependencia pasa naturalmente a integrarse a la tradición de estudios latinoamericanos en Estados Unidos (Berger 1996, 106-122). Para que la teoría de la dependencia no se pierda en el concierto universal de las teorías apropiadas por los estudios latinoamericanos en U.S. y la teoría de la dependencia quede reducida a un simple sistema conceptual desencarnado, conviene no perder de vista el lugar (históricamente geográfico y colonialmente epistemológico) de enunciación. Fundamental en esta operación de desplazamiento y de descolonización intelectual y académica, a la que Berger no contribuye a pesar quizás de sus buenas intenciones, se necesita leer, comentar y reproducir los argumentos de Fernando Enrique Cardoso sobre el consumo de la teoría de la dependencia en Estados Unidos (Cardoso 1972, 1973, 1993). En cuanto a la teoría del colonialismo interno, su importancia en la trayectoria del pensamiento crítico en América Latina es fundamental, cualquiera sean las posiciones o críticas en cuanto a su formulación. A pesar de los treinta años transcurridos desde sus primeras formulaciones (González Casanova 1965, Stavenhaguen 1965, 1986, 1990), hasta su continuidad en la actualidad (Rivera Cusicanqui 1993, Stavenhaguen 1990), la teoría del colonialismo interno (a pesar de sus vinculaciones obvias con el "poscolonialismo" y el "posoccidentalismo"), quedó oscurecida por el valor mercantil adquirido por proyectos semejantes surgidos de legados coloniales con más valor de cambio que los diferidos colonialismo español y portugués.

El argumento de Fernández Retamar se desarrolla en una tensión constante entre el proyecto ideológico del marxismo en el contexto de la revolución cubana, y la cuestión étnica en la historia de América. En verdad, el mismo párrafo citado más arriba, donde se introduce "posoccidentalismo" ligado a la lucha de clases, comienza con una clara alusión a la cuestión étnica ("Indios y negros, pues, lejos de constituir cuerpos extraños a nuestra América por no ser 'occidentales', pertenecen a ella con pleno derecho: más que los extranjerizos y descastados 'civilizadores”'). La cuestión étnica le permite a Retamar introducir una ruptura fundamental en el relato histórico de las Américas, cuyas consecuencias no se han explotado todavía, quizás debido a la hegemonía del legado colonial hispánico en la construcción de categorías geoculturales en América. "Nuestra América”, que Retamar elabora partiendo de Martí, se articula como palabra-clave y como categoría geocultural a partir de la primera independencia, la independencia haitiana. Las consecuencias que no se han explotado son precisamente las de pensar América no a partir de las independencias de los países hispánicos (o iberoamericanos, incluyendo a Brasil) solamente, sino de la importancia de la independencia haitiana, la cual pone en juego el colonialismo francés en el Caribe, en la configuración geocultural de las Américas. Pero aún antes, la independencia de Norte América en 1776, es la que abre las puertas para la expansión de la categoría de “occidente” a “occidentales americanos”, que conducirá luego ala palabra-clave de "hemisferio occidental”. Esto es, las “Indias Occidentales” de 
las colonias hispánicas van dando lugar, paulatinamente, al "hemisferio occidental”, una trayectoria ideológica y geocultural si no opuesta, al menos significativamente diferente al "Orientalismo". Si bien el "occidentalismo" es parte integral de la ideología de la expansión colonial, no tiene la misma configuración histórica que el “orientalismo”. De ahí que sea posible y coherente ligar el pensamiento poscolonial y concebirlo como su contrapartida crítica, en tanto que la poscolonialidad resulta ajena a las discusiones en América Latina. Por la misma lógica, posoccidentalismo es la palabra-clave que encuentra su razón en el occidentalismo que caracteriza los acontecimientos y la discursividad del Atlántico (norte y sur), desde principios del siglo XVI. Posoccidentalismo, repitamos, concebido como proyecto crítico y superador del occidentalismo que fue el proyecto pragmático de las empresas colonizadoras en las Américas desde el siglo XVI, desde el colonialismo hispánico, al norteamericano y al soviético.

Fernández Retamar, en el artículo citado, señala tres momentos de ruptura en los que se van construyendo etapas hacia una proyección posoccidental en las cuales, sin embargo, América como los márgenes de Occidente, no tiene el mismo papel en el orden mundial que Asia como la encarnación de lo oriental. Esos tres momentos son, la independencia haitiana entre finales del siglo XVIII y comienzos del XIX; las independencias de los países iberoamericanos a partir de 1810; y la independencia de Cuba en 1898. Mientras que los dos primeros momentos están caracterizados por la independencia de colonialismos territoriales, el tercer momento de ruptura — como ya dijimos — se caracteriza por la tensión entre el desprendimiento de un colonialismo decadente y la emergencia de un nuevo tipo de colonialismo imperial, surgido del primer movimiento de independencia en las Américas, que lleva a Martí a hablar de "nuestra América” (aquella de los tres momentos de ruptura), como distinta de la otra América (aquella que consiguió su independencia en1776). Por eso es importante subrayar lo que Fernández Retamar nos recuerda: que la revolución haitiana es el inicio de la independencia de "nuestra América”. Y al mismo tiempo, es la que pone en tensión la cuestión étnica con la cuestión de clase: el emergente grupo criollo, sobre todo en el Caribe y en las economías de plantación, no ve con buenos ojos la independencia ligada a la emancipación étnica. La tensión entre clase y etnia, en la independencia haitiana, pone sobre el tapete el hecho de que el proyecto posoccidentalista no puede gestarse sólo sobre la base de la lucha de clases, sino que debe igualmente forjarse en la memoria de los tres grandes genocidios de la modernidad, en los cuales las Américas están implicadas: el genocidio indígena con la llegada de los españoles; el genocidio de la diáspora africana; y el genocidio cuya gestación la encontramos en la gestación misma de la modernidad (e.g., la expulsión de los judíos de España) y que eclosiona en el corazón de Europa y marca la crisis del proyecto de la modernidad. Una crisis que pone también en tela de juicio la idea de que la modernidad es un proyecto todavía inconcluso (Habermas, 1987). La crisis de la modernidad que se manifiesta en el corazón de Europa tiene como respuesta la emergencia de proyectos que la trasciendan: el proyecto posmodernista, en y desde la misma Europa (Hannah Arendt, Lyottard, Vattimo, Boudrillard) y U.S. (Jameson), (la “América Occidental” de Toynbee); el proyecto poscolonialista en y desde la India y el medio oriente (Said, Guha, Bhabha, Spivak); desde América Latina (Retamar, Dussel, Kusch, Rivera-Cusicanqui). En resumen, la crisis del proyecto de la modernidad dio lugar, al mismo tiempo, a que surgieran otros 
que lo superaran: los proyectos que se van gestando en el pensamiento posmoderno, poscolonial y posoccidental. Cada uno de ellos se va articulando a la vez que van rearticulándose también nuevas localizaciones geográficas y epistemológicas que contribuyen al desplazamiento de las relaciones de poder arraigadas en categorías geoculturales e imperiales que, en los últimos cincuenta años, se vio dominada por los estudios de áreas concomitantes con el ascenso a la hegemonía mundial de los Estados Unidos. Es decir, lo que la etnología comparada fue para los primeros proyectos coloniales tempranos (España, Portugal; Pagden 1982), los estudios comparados de las civilizaciones (Said 1978) y el surgimiento de la antropología moderna (Inglaterra, Francia; Fabian 1983, Amselle 1990) fue para los proyectos coloniales modernos, los estudios (comparados) de áreas lo fueron para el colonialismo posmoderno en la etapa actual de globalización (Chomsky 1968). En esta línea de razonamiento, el proyecto inconcluso de la modernidad, es el proyecto inconcluso de los sucesivos colonialismos, y los legados coloniales activos en la etapa actual de un capitalismo sin fronteras (Held 1995). Entiendo, entonces, los tres "pos” como proyectos críticos de superación del proyecto de la modernidad, de una democracia global apoyada en un capitalismo sin fronteras (Held 1995), proyectos que actualizan y activan, al mismo tiempo, la descentralización y la ruptura de la relación entre áreas culturales y producción de conocimiento. Esto es, constribuyen a la restitución de las historias locales como producción de conocimientos que contribuyen a desafiar, sustituir y desplazar las historias y epistemologías globales que buscan su rearticulación en un momento en que el sujeto desencarnado del conocimiento postulado por Descartes y articulado en la modernidad, es cada vez más difícil de sostener (Haraway 1991; Sandoval 1994; Hook and West 1991: Alcoff and Potter 1993).

Volvamos, pues, a las implicaciones del “posoccidentalismo” como respuesta crítica, desde los legados coloniales en América Latina, al proyecto de la modernidad en la distribución de la labor intelectual y científica en la última etapa de occidentalización: aquella liderada por Estados Unidos desde 1945 y que dio lugar a la ruptura de la complicidad natural entre capitalismo y occidente, con la entrada del este asiático en la escena mundial, situación que afrontó la pregunta paradójica de si es posible "la occidentalización del oriente”.

Mientras que la primera parte de este artículo giró en torno a "Nuestra América y Occidente,” de un intelectual cubano, esta segunda parte de mi estudio se desarrolla primero- en torno a las políticas culturales y de investigación que se implementan en Estados Unidos después de la segunda guerra mundial y que hacia mediados de 1970 ya han creado una imagen creciente del Tercer Mundo (y de América Latina) como objeto de estudio de las ciencias sociales practicadas en Estados Unidos (Cline 1966; Pletsch 1981; Berger 1993 y 1996; Mignolo 1993, 1994); segundo, en torno a la emergencia de un nuevo tipo de trabajo, ligado a la creciente emigración de intelectuales desde América Latina a Estados Unidos, que inaugura una epistemología fronteriza entre las exigencias epistemológicas de las ciencias sociales y las expectativas políticas de la reflexión intelectual. La situación es compleja puesto que, por un lado, nos encontramos con el trabajo de académicos motivados por un interés intelectualmente genuino por la situación histórico-social en América Latina (Cline 1966) y, por otro, con los intereses de estado compaginando las investigaciones de áreas con los diseños imperiales (Berger 1996, 1- 
24). Se plantea la reduplicación y continuación del marco que ya encontramos en el siglo XVI: el genuino interés de los misioneros por cristianizar, y los intereses imperiales de la corona de España y Portugal por anexar territorios y gentes a sus dominios.

Pero antes conviene recordar una larga trayectoria en la cual las Indias Occidentales, el Nuevo Mundo y, finalmente, América, son las sucesivas palabras claves de macrorelatos del Occidentalismo para extenderse e incorporar las Indias Occidentales, etc. Las diferencias radicales entre el Occidentalismo y el Orientalismo es, primero, que el Occidentalismo comienza a gestarse afines del siglo XV, con la emergencia en el panorama de la cristiandad occidental de las "indias occidentales"; segundo, el occidentalismo -contrario al "orientalismo” es el discurso de la anexión de la diferencia, más que la creación de un opuesto irreductible, el "Oriente”. Precisamente, "Indias Occidentales” es el nombre que anexa la diferencia al estado y es el nombre que se mantiene en todo el discurso legal del imperio, hasta su caída. "Nuevo Mundo” y "América" comienzan a articularse más tarde, como discurso de la "cultura" no como discurso del "estado".

Habría pues tres grandes momentos del “occidentalismo”: el de los grandes discursos justificando la anexión y la conversión, y que son los discursos producidos durante y en complicidad con el imperio hispánico: Bartolomé de las Casas, Historia de las Indias (circa 1545), Breve historia de la destrucción de las Indias Occidentales (1542); Apologética Historia Sumaria (circa 1555), Juan López de Velazco, Geografía y descripción universal de las Indias (1571-74) y José de Acosta, Historia Natural y Moral de las Indias (1590). Todas estos relatos del siglo XVI que configuran el macro-relato del primer momento del occidentalismo, continúa hasta finales del XVIII donde nos encontramos, por ejemplo, Antonio Alcedo y Herrera, Diccionario Geográfico de las Indias Occidentales (1786-1789). La fractura en el macro-relato hispánico la notamos por esa fecha, cuando Juan Bautista Muñoz, el último gran historiador oficial del imperio y creador del Archivos de Indias, escribe Historia del Nuevo Mundo (1793). Muñoz anuncia la quiebra y el fin del occidentalismo basado en las “Indias Occidentales” para plegarse a la denominación que es introducida por los nuevos imperios emergentes, y constructores de nuevos relatos en torno a la noción de “América” y "Nuevo Mundo”. Estos relatos, contrarios a los anteriores, desplazan la hegemonía del occidentalismo de España a Francia y Alemania.

Esos dos nuevos macros-relatos los atribuyó Anthony Pagden (Pagden 1992) el uno a Lafitau y el otro a Humboldt; el primero ubicando los “americanos” en el concierto planetario; el segundo, ubicando al "Nuevo Mundo" en el concierto de la naturaleza y la historia. El segundo relato del occidentalismo, anclado en Joseph Francois Lafitau, Mouers des sauvages ameriquains, comparées aux moeurs des premiers temps (1724), es el relato de la conversión de los “salvajes” y “caníbales” alejados en el espacio (e.g., Indias Occidentales) a "primitivos” alejados en el tiempo. El paradigma al que contribuye Lafitau, es el gran paradigma de la modernidad en el cual el planeta y la historia universal se piensa en relación a un progreso temporal de la humanidad de lo primitivo a lo civilizado (Fabian 1982). Para Pagden, este relato encontró su momento de cierre después de 1950, con los sucesivos movimientos de descolonización en África, Asia y el Caribe. En cambio, el relato que inaugura Humboldt (Cosmos: Sketch of a physical description of the universe, 1846-58), re-piensa el Nuevo Mundo en el momento de auge de las investigaciones 
científicas, impulsadas por la revolución industrial, hacia finales del XVIII y comienzos del XIX. Este tercer relato, en el que la modernidad se piensa en torno al progreso de la investigación científica, lo considera Pagden todavía vivo en proyectos como los de T. Todorov cuando considera que "todos descendemos de Colón” (1982). Esto es, el relato de Humboldt tiene todavía vigencia en la construcción de Europea de su propia identidad, la cual mucho depende del viaje de Colón y su importancia en la construcción de los tres grandes relatos del occidentalismo. Son, prescisamente, esos grandes relatos los que Edmundo O'Gorman trató de desmontar en dos de sus libros fundamentales, La idea del descubrimiento de América (1955) y La invención de América (1958). Ahora bien, antes de llegar a este momento del anti-occidentalismo, como lo muestra el recorrido de Fernández Retamar en el artículo comentado más arriba, hay unos ciento y tantos años de anti-occidentalismo elaborado por la inteligencia criolla-americana. El anti-occidentalismo establece una particular relación con los tres grandes relatos que mencioné más arriba: el gran relato de las Indias Occidentales es el pasado concluido; en tanto que el gran relato de la conversión de los salvajes en el espacio y en el tiempo, y el gran relato del la tecnología y la modernidad le son contemporáneos. El relato del anti-occidentalismo surge coetáneamente al de Humboldt, posterior a la mayoría de los movimientos de independencia, y se va gestando en torno a la transformación de “Indias Occidentales” (palabra-clave del discurso del imperio hispánico) y de “América/Nuevo Mundo” (palabra-clave empleada en el “corazón de Europa”, según Hegel), por “América” y “Nuestra América”. Esto es, estas dos últimas son las palabras-claves sobre las que se va articulando el discurso antioccidental en América. Fernández Retamar, a partir de la experiencia de la revolución cubana, intenta desviar el discurso anti-occidental hacia uno posoccidental. Pero lo hace también en el momento en el que el discurso de Humboldt, quizás vigente en Europa, ha perdido ya toda vigencia en Estados Unidos con la emergencia de los estudios de área y la transformación de “América Nuevo Mundo” en “América Latina” como objeto de estudio de las ciencias sociales. ¿Es esto posible? Y si lo es, ¿¿cuáles serían las posibles configuraciones?

El punto de referencia a partir de aquí es el artículo de Fernando Coronil "Beyond Occidentalism: Toward Post-Imperial Geocultural Categories” (Coronil 1996). El artículo de Coronil no se dirige a los tres grandes relatos del occidentalismo que comenté más arriba. Quizás no es por casualidad que siendo Coronil educado en Venezuela y comprometido con la historia social y política de América Latina sea “occidentalismo” (y no "modernismo" o "colonialismo") la palabra-clave que sugiere pensar la trascendencia de la modernidad. Sin duda, el “más allá” aquí no debería entenderse en un sentido literal, e imaginar que el occidentalismo (como los estados-naciones) tiene fronteras geográficas y legales y que “ir más allá” del occidentalismo es una figura similar a ir más allá de México y cruzar la frontera a Estados Unidos. Interpreto “ir más allá” en el plano de las categorías geoculturales que invoca Coronil, como un trascender tales categorías manteniendo las de la epistemología moderna, y trascenderlas en la integración de lo que esas mismas categorías negaron. La incorporación de la negación en lo que la categoría afirma, es al mismo tiempo su superación. Así, en la medida en que “civilización” sirvió como una categoría que negó poder de conocimiento a la "barbarie”, la incorporación de la barbarie en los términos negados por la civilización, es lo que permite trascenderla no reivindicando 
su opuesto (la barbarie) sino reivindicando la fuerza de la frontera que crea la posibilidad de la barbarie de negarse a sí misma como barbarie-en-la-otredad; de revelar la barbarieen-la-mismidad que la categoría de civilización ocultó (Hobsbawm 1994, Mignolo por aparecer); y de generar un nuevo espacio de reflexión que mantiene y trasciende el concepto moderno de razón, enquistado en la ideología de las ciencias sociales en complicidad con los diseños de la expansión colonial (Wallerstein et. al., 1996, 1-32). Esto es, la generación de una epistemología de frontera DESDE varios espacios del Tercer Mirado configurado por diferentes legados coloniales, PARA el conocimiento y la civilización planetaria (e.g., no una epistemología sólo para los marginados, o “del Tercer Mundo para el Tercer Mundo”, lo cual mantiene la hegemonía y universalidad del conocimiento producido en el no-lugar y en la objetividad de los proyectos imperiales) (Mignolo 1996).

El artículo de Coronil destaca, en primer lugar, la persistencia de las estrategias del discurso colonial y de la modernidad para construir una mismidad (e.g., Occidente) que aparece como construcción de la otredad (e.g., Oriente, Tercer Mundo, barbarie, subdesarrollo, etc.). Partiendo de la construcción del orientalismo analizada por Said (Said 1986), Coronil se plantea examinar no la construcción del oriente, sino la noción misma de oeste en la creación occidental del orientalismo:

Occidentalism, as I define it here, is thus not the reverse of Orientalism but its condition of possibility, its dark side (as in a mirror) (...) Given Western hegemony, however, opposing this notion of "Occidentalism" to "Orientalism" runs the risk of creating the illusion that the terms can be equalized and reversed, as if the complicity of power and knowledge entailed in Orientalism could be countered by an inversion.

What is unique about Occidentalism as I define there, is not that it mobilizes stereotypical representations of non-Western societies, for the ethnocentric hierarchization of cultural difference is certainly not a Western privilege, but that this privilege is intimately connected to the deployement of global power.

Challenging Orientalism, I believe, requires that Occidentalism be unsettled as a style of representation that produces polarized and hierarchical concepts of the Westand its Others and makes them central figures in accounts of global and local histories (Coronil 1996, 56-57).

Occidentalismo es, para Coronil, una serie de estrategias cognoscitivas, ligadas al poder, las cuales dividen el mundo en unidades bien delimitadas; separan las conecciones entre sus historias; transforman las diferencias en valores; naturalizan tales representaciones; e interviene, a veces sin designios perversos (lo cual no es necesariamente justificable) en la reproducción de relaciones asimétricas de poder. Para explicitar tal caracterización, Coronil analiza tres estrategias particulares en la auto-construcción del occidentalismo:

a) La disolución del Otro en el Mismo. En tal modalidad, se considera el Oeste y lo No-Occidental como entidades autónomas y opuestas, y la oposición se resuelve mediante la incorporación de las zonas y las comunidades no-occidentales, en la marcha triunfal de la expansión occidental;

b) La incorporación del Otro en el sí Mismo. En esta segunda modalidad, la atención que se presta al Oeste en la construcción de la modernidad oscurece, a veces sin 
proponérselo, el papel que las comunidades no-occidentales tuvieron y tienen en la construcción de la modernidad. Es precisamente esta modalidad la que oscurece y reprime el papel de los intelectuales no-occidentales en la construcción de un conocimiento planetario (Dussel, 1995);

c) La desestabilización del Mismo por el Otro. En esta modalidad, son los intelectuales y académicos de izquierda, críticos de la modernidad y del colonialismo, quienes mantienen y reproducen la idea del Otro, esta vez como un espejo crítico donde se pueden observar "nuestras" propias limitaciones.

¿Cuáles son las posibilidad de “trascender el occidentalismo” construyendo categorías geohistóricas que no sean imperiales? Coronil lo formula partiendo de la rearticulación de historia y geografía no sólo como categorías que organizan el mundo temporal y geográficamente, sino como prácticas disciplinarias que sostienen estructuras de poder. La subordinación de la geografía a la historia, en la construcción misma de la modernidad, apagó la importancia de las historias locales y las subordinó a la historia universal de Occidente. La etapa actual de globalización, no sólo por la creciente magnitud de las corporaciones transnacionales sino también por sus objetivos, restituyen la importancia del espacio y hacen cada vez más difícil pensar en términos de historias universales (de las historias del mundo: Hodgson 1993; Bright and Geyer 1987, 1996). O, lo que es lo mismo, al restituir el espacio restituyen las historias locales y al restituir las historias locales disminuyen la idea de una dupla constante entre Occidente y el resto del planeta. Las transnacionales van creando un mundo global que opera de arriba hacia abajo, más que desde un centro a la periferia. En esta rearticulación, la cuestión de la “otredad” pierde relevancia y comienza a ser desplazada por estructuras económicas globales y políticas trans-estatales que hacen más visible la "subalternidad" que la otredad; subalternidad, claro está, que sobrepasa el marco de las clases sociales y crea las condiciones para la multiplicación de movimientos sociales y para la rearticulación de la sociedad civil. La pregunta que subsiste, sin embargo, es si la rearticulación del orden mundial por la expansión cada vez mayor y transnacional del capital necesita, como justificación ideológica, una distribución geo-cultural en las que se preserven las categorías forjadas por el occidentalismo. La entrada en el concierto mundial del este asiático hace cada vez más difícil mantener la imagen de un mundo partido entre occidente y el resto. Las múltiples formas de teorización y conceptualización que se organizan en torno a palabrasclaves como posmodernidad, poscolonialidad, posoccidentalismo están desarticulando las conceptualizaciones del discurso de la modernidad y poniendo de relieve un nuevo mapa en el que no se sostienen las categorías de pensamiento del occidentalismo. En palabras de Coronil:

The result of these changes (e.g., de la última etapa de globalización y la creciente polarización de las clases sociales a nivel mundial, de migraciones masivas, forzadas o voluntarias, de creciente tecnoglobalismo, etc. WM) familiar spatial categories are uprooted from their original sites and attached to new locations. As space becomes fluid, history can no longer be easily anchored in fixed territories. While deterritorialization entails reterritorialization, this process makes more visible the social constructedness of space, for this "melting" of space is met partly with the "freezing" of history (...) This spatialization of time serves as the location of new social movements, as well as of new 
targets of imperial control; it expands the realm of imperial subjection but also of political contestation. As a result of these transformations, contemporary empires must now confront subaltern subjects within reconfigured spaces at home and abroad, as the Other, once maintained on distant continents or confined to bounded locations at home, simultaneously multiplies and dissolve. Collective identities are being defined in fragmented places that cannot be mapped with antiquated categories (Coronil 1996: 79$80)$.

Cité en extenso a Coronil, porque sus conclusiones a un argumento que busca formas posibles de trascender el occidentalismo mediante la rearticulación de las categorías de historia y geografía, tiempo y espacio, memoria y localización, no sólo desplaza categorías disciplinarias sino que reclama nuevas categorías geo-históricas que desplacen a su vez las construidas por la modernidad. En consecuencia, dos tareas se presentan con cierta urgencia en el pensamiento latinoamericano (Roig 1981) y en los estudios latinoamericanos (Berger 1993). Una es la de repensar la conceptualización misma de América Latina que revisa y ordena Fernández Retamar en el momento en que las utopías socialistas han caído, el capital internacional comienza a construir nuevas regiones (MERCOSUR, NAFTA), (Castañeda 1994: 198-326) y el Caribe gana terreno en los proyectos transnacionales hacia América del Sur, y las migraciones corroen las supuestos lazos entre territorio y cultura. La otra, ligada a la anterior, es la de repensar las relaciones entre pensamiento latinoamericano y estudios latinoamericanos en el ámbito de la producción intelectual y académica. Las configuraciones actuales de ambas (conceptualización geo-histórica e intelectual/ académica) se mantienen todavía en los marcos de la epistemología moderna. La necesaria contribución de proyectos posoccidentalistas, como continuación de lo esbozado hace veinte años por Fernández Retamar y retomado —indirectamente_- por Coronil, será pues la de construir — por un lado— América Latina en la nueva escena global y — por otroconstruir el puente entre pensamiento EN América Latina y estudio DE América Latina. El primero, en su constante reflexión sobre la occidentalización a partir de las independencias, contribuyó a forjar un pensamiento crítico derivado de las historias locales (Mignolo 1994-96). El segundo, en su constante reflexión SOBRE América Latina a partir de 1900, consolidado en la creación de LASA en los 60' en el contexto de la gestación de los estudios de área ligados al liderazgo mundial de Estados Unidos, contribuyó a forjar un conocimiento directa o indirectamente motivado por los diseños globales (Mignolo por aparecer). El informe de la Comisión Gulbenkian (Wallerstein et. al., 1996) es un buen ejemplo de nuevos diseños globales urgidos por la situación crítica de las ciencias sociales y de los estudios de área, ambos ligados a las expansiones coloniales, en una etapa histórica que se construye autocríticamente en torno a los "pos" (modernismo, colonialismo, occidentalismo). Las respuestas a qué tipo de ciencias sociales son necesarias para el mañana no debería ser ofrecida, solamente, a partir de la experiencia de las ciencias sociales que el informe critica, desde su gestación en 1850 hasta 1945, y desde 1945 hasta la fecha (e.g., durante la hegemonía de Inglaterra, Francia y Alemania hasta 1945; de Estados Unidos a partir de 1945). Por eso, en el caso particular de América Latina, la perspectiva posoccidentalista como perspectiva crítica de pensamiento tendrá un papel fundamental si no se quiere continuar reproduciendo la estructura de los estudios de área, en su formulación y práctica desde 1950 hasta 1990. 
¿Y qué de las humanidades? La práctica literaria y filosófica, el ensayo (histórico, antropológico, literario, filosófico, etc.) en América Latina fue y es el espacio donde se gestó y manifestó un “pensar” al margen de las disciplinas. La explicación del fenómeno la conocemos (Mignolo 1993, 1994). En la medida en que la práctica académica y científica (ciencias sociales) se asienta en las regiones de gran desarrollo económico y tecnológico, y se basa en ellos, las regiones de menor desarrollo económico y tecnológico no pueden competir o mantenerse al mismo nivel en la producción de conocimientos. La tarea intelectual académica se divide entonces entre zonas donde se produce "conocimiento" SOBRE ciertas regiones o áreas y zonas EN donde se produce "cultura” (sigo aquí la nomenclactura de Pletsch 1981; Mignolo 1993, 1994; 1996). Esta distinción no niega la posibilidad de la producción de "conocimientos” (e.g., práctica en ciencias sociales) en zonas de capacidades económicas y tecnológicas como América Latina (Marini y Millan, 1994), pero sí quiere destacar las desventajas materiales para el ejercicio de tales prácticas disciplinarias. Paulin J. Hountondji (Hountondji 1988) llamó la atención de los científicos sociales en África con respecto a las limitaciones de sus propias prácticas:

In fact, it seems urgent to me that the scientists in Africa, and perhaps more generally in the Third World, question themselves on the meaning of their practices as scientists, its real function in the economy of the entirety of scholarships, its place in the process of production of knowledge on a world-wide basis ... Scientific activity in the Third World seems to me to be characterized, globally, by its position of dependency. This dependency is of the same nature as that of the economic activity, which is to say that, put back in the context of its historical genesis, it obviously appears to be the result of the progressive integration of the Third World into the worldwide process of production of knowledge, managed and controlled by the Northern countries (Hountondji [1988],1992, 239-240).

Las ciencias sociales estuvieron, y en alguna medida todavía están, ligadas a las empresas colonizadoras. No es necesario buscar intelectuales de izquierda para apoyar tal enunciado; el informe de la Comisión Gulbenkian narra este proceso desde 1850 hasta 1990. Las ciencias sociales se gestaron en las lenguas imperiales del momento (inglés, francés y alemán) y en el presente se mantienen en inglés. Quedaría por analizar la relación entre ciencias sociales y otras lenguas, no sólo de otras lenguas menores de la modernidad en relación a las ciencias sociales (italiano, español, francés), sino también de lenguas con número elevado de hablantes y de larga data (e.g., chino, árabe, hebreo)y, más problemático aún, las consideradas "lenguas nativas” en el concierto planetario de la modernidad (Wiredu 1992). En la organización del mundo promovida por el occidentalismo (e.g., la modernidad), las ciencias se articularon en determinadas lenguas y localizaciones geográfico-epistemológicas. Más allá de las ciencias sociales quedaron las prácticas de pensamiento. La reorganización de la producción del conocimiento, desde una perspectiva posoccidentalista, tendría que formularse en una epistemología fronteriza en la cual la reflexión (filosófica, literaria, ensayística) incorporada a las historias locales encuentra su lugar en el conocimiento des-incorporado de los diseños globales en ciencias sociales.

A manera de conclusión y apertura hacia una nueva dirección del argumento, mencionaré una vez más la contribución fundamental de Gloria Anzaldúa a lo que Coronil proyecta e imagina en términos de "nonimperial geohistorical categories”. Borderland/La 
Frontera no sólo es un momento teórico fundamental para la construcción de categorías geo-culturales no imperiales, sino que lo es precisamente por indicar una dirección posible para trascender el occidentalismo no sólo en lo que atañe a las categorías geo-culturales sino también en la necesidad de una epistemología fronteriza, posoccidental, que permita pensar y construir pensamiento a partir de los intersticios y a aceptar que los inmigrantes, los refugiados, los homosexuales, etc., son categorías fuera de la ley desde una epistemología monotípica que normaliza determinados espacios (nacionales, imperiales), como espacios de contención y de marginación. El giro brutal que propone Borderland/Lafrontera escrito con la fuerza y el sentimiento de Hargill, Texas (un espacio producto de sucesivos colonialismos y articulaciones imperiales) es quizás equivalente al que produjo Descartes con su Discours de la méthode, escrito en el seno de Amsterdam, Holanda cuando un reacomodo de las fuerzas imperiales la conviertieron en centro del comercio planetario. Esta es, en cierta manera, la lectura que hace Norma Alarcón, al compararla contribución teórica de Anzaldúa con producciones teóricas más canónicas:

No se desea tanto producir un contradiscurso, sino aquel que tenga un propósito desidentificatorio, que dé un viraje drástico y comience la laboriosa construcción de un nuevo léxico y unas nuevas gramáticas. Anzaldúa entreteje auto-inscripciones de madre/ hija/ amante que a pesar de que no se simbolicen como una "metaforización primaria" del deseo, evitarán que las "mujeres tengan una identidad en el orden simbólico que sea distinta de la función maternal y por lo tanto les(nos) impiden constituir una verdadera amenaza para el orden de la "metafísica occidental", o si se quiere, pare el "romance familiar/nacional/etno-nacional”. Anzaldúa está comprometida con la recuperación y reescritura de ese "origen" femenino/ista no sólo en los puntos de contacto de varias simbolizaciones, sino en la misma frontera geopolítica de El Valle ... Un espacio externo que es presentado en la forma de la Texas de Estados Unidos, la frontera sudoeste con México ... y una frontera psicológica, la frontera sexual y espiritual (Alarcón 1996, 14445).

En Anzaldúa se cruzan los ciclos imperiales, desde el relato de las Indias Occidentales hasta el de América Latina como objeto en los estudios de áreas. El suyo, equivalente y continuador de los discursos pan-occidentales del siglo XIX y de los primeros años del XX, en América Latina, se proyecta hacia un pensar posoccidental en donde las categorías geohistóricas no-imperiales, que busca Coronil, encuentran su espacio de gestación en el cruce de las experiencias históricas imperiales con las categorías sexuales y la germinación de una epistemología fronteriza que va mas allá de las construcciones binarias del occidentalismo.

\section{BiBLIOgRAFÍA}

Alarcón, Norma. "La Frontera de Anzaldúa. La inscripción de una ginocrítica”. B. González Stephan (comp.). Cultura y Tercer Mundo. Tomo 2. Nuevas Identidades y Ciudadanías. Caracas: Editorial Nueva Sociedad, 1996. 121-146.

Alcoff, L. and E. Potter. Feminist Epistemologies. New York: Routledge, 1993. Amselle, Jean-Loup. Logiques métisses. Anthropologie de l'identité en Afrique et ailleurs. Paris: Payot, 1990. 
Berger, Mark T. "Civilizing the South: The US Rise to Hegemony in the Americas and the Roots of 'Latin American Studies’ 1898-1945". Bulletin of Latin American Research 12/1 (1993): 1-48.

Under Northern Eyes. Latin American Studies and U.S. Hegemony in the Americas, 1898-1990. Bloomington: Indiana University Press, 1996.

Bright, Ch. and M. Geyer. "For a Unified History of the World in the Twentiteh Century". Radical History Review 39 (1987): 69-91.

"World History in a Global Age”. The American Historical Review 100 (1995): 1034-1060.

Cardoso, Fernando Enrique. “Dependency and Development in Latin America”. Latin American Research Review vol. 19 (1972).

“Imperialism and Dependency in Latin America”. F. Bonilla and R. Girling (eds.). Structures of Dependency. Stanford: Institute of Political Studies, 1973. As Idéias e seu Lugar. Ensaios sobre as teorias do desenvolvimento. Petrópolis, 1993.

Castañeda, Jorge. G. Utopia Unarmed. The Latin American Left after the Cold War. New York: Random House, 1994.

Castro-Gómez, Santiago. “Narrativas contra modernas y teorías poscoloniales. La propuesta hermenéutica de Walter Mignolo”. Critica de la razón latinoamericana. Barcelona: Puvill Libros, 1996. 145-170.

Chomsky, N. American Power and the New Mandarins. New York: Pantheon, 1968.

Cline, Howard. "The Latin American Studies Association: A Summary Survey with Appendix”. Latin American Research Review.

Coronil, Fernando. "Beyond Occidentalism: Toward Non imperial Geohistorical Categories”. Cultural Anthropology 11/1 (1996): 51-87.

del Barco, Oscar. Esbozo de una crítica a la teoría y práctica leninistas. Puebla: Universidad Autónoma, 1980.

Dussel, Enrique, The Underside of Modernity. Apel, Ricoeur, Rorty, Taylor, and The Philosophy of Liberation. Humanities Press, 1996.

Escobar, Arturo. "Conclusion: Imagining a Postdevelopment Era”. Encountering Development. The Making and Unmaking of the Third World. Princeton: Princeton University Press, 1995.

Fabian, Johannes. Time and the Other. How Anthropology Makes its Object. New York: Columbia University, 1983.

Fernández Retamar, Roberto. “Nuestra América y Occidente”, Casa de las Américas 98 (1976): 36-57.

González-Casanova, Pablo. "Internal colonialism and national development”. Studies in Comparative International Development 114 (1965).

Gunder Frank, Andre, Latin America: Underdevelopment or Revolution: Essays on the Development of Underdevelopment and the Immediate Enemy. New York: Monthly Review Press, 1969.

Habermas, Jurgen, The Philosophical Discourse of Modernity. (Translated by F. Lawrence). Boston: M.I.T. Press, 1987. 
Hall, Stuart. "The Local and the Global: Globalization and Ethnicity”. A. King, (ed.). Culture, Globalization and the World-System, 1991. 19-40.

"Old and New Identities, Old and New Ethnicities”. A. King, (ed.). Culture, Globalization and the World-System, 1991. 41-68.

Haraway, Donna J, "Situated Knowledges: The Science Question in Feminism and the Privilege of Partial Perspective”. Simians, Cyborgs and Women. The Reinvention of Nature. Routledge: New York, 1991. 183-203.

Held, David. Democracy and the Global Order. From the Modern State to Cosmopolitan Governance. Stanford: Stanford University Press, 1995.

Hobsbawm, Eric. “Barbarism: A User’s Guide”. New Left Review 206 (1994): 44-54.

Hodgson, Marshall G. S. Rethinking World History. Essays on Europe, Islam, and World History. Edited with and Introduction and Conclusion by Edmund Burke, III. New York: Cambridge University Press, 1993.

Hook, bell and West, Cornel. Breaking Bread. Insurgent Black Intellectual Life. Boston: South End Press, 1991.

Hountondji, Paulin J. "Recherche et extraversion: Elements pour une sociologic de la science dans les pays de la périphérie” (1988). Reprinted in V. Y. Mudimbe, (ed.). The Surreptitious Speech, 1992. 238-248.

King, Anthony D. Culture, Globalization and the World-System. Contemporary Conditions for the Representation of Identity. Binghamton: Department of Art and History, 1991.

"Introduction: Spaces of Culture, Spaces of Knowledge”. A. King, (ed.). Culture, Globalization and the World-System, 1991. 1-18.

Kusch, Rodolfo. El pensamiento indígena y popular en América. Buenos Aires: Hachette, 1970.

Marini, Mauro y M. Millón. La teoría social Latinoamericana: Tomo 1, Los orígenes; Tomo 2, Subdesarrollo y dependencia. México: El caballito de batalla, 1994.

Marx, Karl. "The future results of the British rule in India” (1853). Marx/Engels, On Colonialism. Moscow: Progress Publishers, 1974. 81-88.

Mignolo, Walter D. “Are Subaltern Studies Postmodern or Postcolonial?” Dispositio 46 (1994-96): 45-73.

"Bi-Languaging Love: National Identifications and Cultures of Scholarship in a Transnational World”. P. C. Pfeiffer and L. García-Moreno, (eds.). Text and Nation. Columbia: Camden House, 1996. 123-142.

"Human understanding and (Latin) American Interests: The politics and sensibilities of geocultural locations”. Poetics Today 16:1 (1995): 171-214.

“Colonial and Postcolonial Discourses: Cultural Critique or Academic Colonialism?” Latin American Research Review 28 (1993): 120-131.

“Occidentalización, imperialismo, globalización: herencias coloniales y teorías postcoloniales”. Revista Iberoamericana 170-171 (1995): 27-40.

“Herencias coloniales y teorías postcoloniales”. Cultura y Tercer Mundo. 1. Cambios en el saber académico. Beatriz González Stephan (ed.). Caracas: Nueva Sociedad, 1996: 99-136. 
Moreiras, Alberto. "La tormenta que sopla del Paraíso: Globalidad negativa y estudios culturales”, por aparecer.

“Elementos de articulación teórica para el subalternismo latinoamericano. Cándido y Borges”. Revista Iberoamericana 176-177 (1996): 885-892.

Mudimbe, V. Y. (ed.). The Surreptitious Speech: Présence Africaine and the Politics of Otherness, 1947-1987. Chicago: The University of Chicago Press, 1992. 238-248.

Pagden, Anthony. The Fall of Natural Man. The American Indian and the Origin of Comparative Ethnology. Cambridge: Cambridge University Press, 1982.

“'Americanism' from Modernity to Post-Modernity”. Paper discussed at the colloque Le Nouveau Monde-Mondes Nouveaux. L 'Experience Americaine. CERMACA, Ecoles des hautes Etudes en Sciences Sociales (Paris, Juin 2-4, 1992).

Pletsch, Carl E. "The Three Worlds, or the Division of Social Scientific Labor, circa 19501975”. Comparative Study of Society and History (1981): 565-590.

Rivera-Cusicanqui,Silvia. "Pachakuti: los horizontes históricos del colonialismo interno". X. Albó, (ed.). Violencias encubiertas en Bolivia, Vol. l. (1993): 33-55.

Roig, Arturo Andrés. Teoría y crítica del pensamiento Latino-Americano. México: F.C.E., 1981.

Said, Edward. “Orientalism Reconsidered”. Literature, Politics and Theory. F. Barker, P. Hulme, M. Iversen and D. Loxley, (eds.). London: Methuen, 1986. Orientalism. New York: Vintage Books, 1978.

Sandoval,Chela. "Re-EnteringCyberspace: Sciences of Resistance”. Dispositio/n 46(19941996): 75-94.

Stavenhagen, Rodolfo, “Classes colonialism and acculturation”. Studies in Comparative Internacional Developement 1/6 (1965).

"Ethnodevelopment: A neglected dimension in development thinking”. R. Anthorpe and A. Krahl, (eds.). Development Studies: Critique and renewal. Leiden: E. J. Brill, 1986.

The Ethnic Question. Conflicts, Development and Human Rights. Japan: United Nations University Press, 1990.

Wallerstein, I. et al. Open the Social Sciences. Report of the Gulbenkian Commisssion on the Restructuring of the Social Sciences. Stanford: Stanford University Press, 1996.

Wiredu, Kwasi. "Formulating Modern Thought in African Languages: Some Theoretical Considerations”. V. Y. Mundimbe, (ed.). The Surreptitious Speech (1992): 301-332. 